\title{
Distribuição dos serovares de leptospira em caninos clinicamente suspeitos no Rio de Janeiro*
}

\section{Leptospira serovars in clinically ill dogs from Rio de Janeiro, Brazil}

\author{
Isabel Maria Alexandre Freire, ${ }^{* *}$ Renato G. Varges, ${ }^{* \star}$ Yuri N. P.Gomes, ${ }^{* *}$ \\ Cecília Riscado Pombo,** Walter Lilenbaum ${ }^{*, * *}$
}

\begin{abstract}
Resumo
A leptospirose é uma doença de distribuição mundial que acomete várias espécies de animais domésticos e de vida selvagem. Diversos serovares podem infectar o cão, podendo ou não determinar manifestações clínicas. Assim, o objetivo do presente estudo foi relatar resultados de provas de imunodiagnóstico em cães clinicamente suspeitos de leptospirose no município do Rio de Janeiro e adjacências. Foram analisadas pelo teste da Soroaglutinação Microscópica com Antígenos Vivos 120 amostras de cães com clínica sugestiva de leptospirose aguda no período de março a novembro de 2004. Destas, 88 (73,3\%) foram reativas. Baseando-se nos títulos alcançados, 25 animais $(20,8 \%)$ apresentaram título mínimo de 800, 63 (52,5\%) entre 200 e 400, e 32 animais (26,7\%) inferiores a 200, sendo portanto consideradas negativas. No que se refere à distribuição por serovares, verificou-se amplo predomínio para a amostra Icterohaemorrhagiae, com 60 amostras reativas (50\%), seguido de Copenhageni, com 19 amostras reativas (15,8\%) e Canicola, com nove amostras reativas (7,5\%). Ao somar-se Icterohaemorrhagiae e Copenhageni, por serem ambas estirpes do mesmo sorogrupo, obtiveram-se 79 amostras sororreativas para este sorogrupo, o que corresponde a $78,4 \%$ das amostras reativas e $57,5 \%$ dos animais estudados. Nenhuma amostra apresentou sororreatividade para os serovares Autumnalis, Bataviae, Grippotyphosa, Pomona ou Bratislava.
\end{abstract}

Palavras-chave: leptospirose, cães, Icterohaemorrhagiae.

\begin{abstract}
Leptospirosis is a worldwide occurring disease which affects several species. Different serovars may affect dogs, determining or not clinical disease. The purpose of this study was to report the results of serological tests on 120 dogs tested by Microscopic Agglutination test in Rio de Janeiro, Brazil. Eighty-eight (73.3\%) samples were reactive. Based on the titers, 25 samples (20.8\%) presented titers e" $800,63(52.5 \%)$ between 200 and 400 and $32(26.7 \%)$ less than 200 . In relation to the serovar distribution, a wide predominance to Icterohaemorrhagiae was observed, with 60 reactive samples (50\%), followed by Copenhageni, with $19(15.8 \%)$ and Canicola (7.5\%) with nine reactive samples. When considered the Icterohaemorrhagiae serogroup, 79 reactive samples were observed, which corresponds to $78.4 \%$ of reactive samples or $57.5 \%$ of studied animals. No sample presented seroreactivity to Autumnalis, Bataviae, Grippotyphosa, Pomona or Bratislava.
\end{abstract}

Keywords: leptospirosis, dogs, Icterohaemorrhagiae.

\section{Introdução}

A leptospirose é uma doença de distribuição mundial e mais freqüente em regiões de clima tropical (Ko et al., 1999). Afeta várias espécies de animais domésticos e de vida selvagem, além do homem, que pode se tornar hospedeiro acidental do agente. As fontes de infecção são os diversos reservatórios que mantêm o agente na natureza, sem apresentar sinais severos da doença e contaminando o ambiente. Os microrganismos então infectam outros indivíduos da mesma espécie que também se tornarão reservatórios, ou então contaminam indivíduos de outras espécies resultando em infecções acidentais (Levett, 2001).

O cão, pela sua estreita convivência com o homem, é considerado como o animal doméstico mais importante dentre os hospedeiros das leptospiras (Abuchaim, 1986). Diversos serovares podem infectar o cão, podendo ou não determinar manifestações clínicas (Hagiwara et al., 2004). O cão é o hospedeiro natural do serovar Canicola (Greene et al., 2000) sofrendo infecção subclínica ou crônica, podendo muitas vezes mostrar-se assintomático. Já o principal

\footnotetext{
*Extraído da tese de mestrado da primeira autora, apresentada ao Programa de Pós-graduação em Medicina Veterinária da Faculdade de Veterinária da UFF.

**Laboratório de Bacteriologia Veterinária, Departamento de Microbiologia e Parasitologia, Universidade Federal Fluminense - UFF. Niterói, RJ

${ }^{* \star *}$ Autor para correspondência. E-mail: mipwalt@vm.uff.br
} 
reservatório do serovar Icterohaemorrhagiae em meio urbano é reconhecidamente o rato de esgoto, Rattus norvegicus, que alberga em seus rins a espiroqueta sem aparentemente sofrer danos consideráveis, contaminando o ambiente através de sua urina. Relatos mostraram ratos com leptospirúria por mais de dois anos. Em nosso meio, o agente pode ser encontrado em cerca de $30 \%$ dos ratos de esgoto (Lilenbaum et al., 1993). Os ratos contaminam o solo, água e alimentos com sua urina ou então são caçados e comidos por cães.

No Brasil o estudo da leptospirose canina iniciou-se no Rio de Janeiro com Dacorso Filho, que em 1940 isolou o agente e identificou-o como serovar Icterohaemorrhagiae. No mesmo ano, Guida isolou Icterohaemorrhagiae e Canicola de cães doentes e relatou em inquérito sorológico de 100 cães, 13\% dos cães reativos para Icterohaemorrhagiae e $18 \%$ para Canicola. Um estudo realizado no Estado de São Paulo com dez cães com suspeita clínica da doença demonstrou 60\% de positividade (Hagiwara e Santa Rosa, 1975). Caldas e colaboradores (1976) analisaram na Bahia 430 amostras de soro e encontraram $22,6 \%$ de aglutinantes para Icterohaemorrhagiae e $24,5 \%$ para Canicola. No Rio de Janeiro, Alves et al. (1989) testaram 75 soros de cães clinicamente suspeitos, encontrando $66,7 \%$ de reações positivas. Mais recentemente, um estudo de sete casos de leptospirose no Rio Grande do Sul revelou predominância do serovar Copenhageni (Santin et al., 2006).

Segundo Santin et al. (2006), trabalhos realizados no Brasil sugerem que os serovares Icterohaemorrhagiae e Canicola são os mais freqüentemente encontrados em caninos no nosso meio. Lilenbaum et al. (1994) encontraram em inquérito sorológico com 745 amostras de cães do Rio de Janeiro a predominância de Canicola (34,1\%), Andamana $(26,1 \%)$ e Icterohaemorrhagiae (21,9\%). Mais recentemente, Favero et al. (2002) observaram Copenhageni (24\%) e Icterohaemorrhagiae $(10,9 \%)$ como os mais freqüentes em análise de 137 amostras séricas de cães em São Paulo.

O objetivo do presente estudo foi relatar resultados de provas de imunodiagnóstico em cães clinicamente suspeitos de leptospirose no município do Rio de Janeiro e adjacências.

\section{Material e métodos}

Amostras - Foram analisadas 120 amostras de soro de cães com sinais clínicos sugestivos de leptospirose aguda provenientes do município do Rio de Janeiro e adjacências no período de março a novembro de 2004. Informações sobre a gravidade do estado clínico, realização do tratamento e recuperação dos animais foram fornecidas pelo médicoveterinário. As amostras sanguíneas, coletadas no momento do exame clínico do animal, foram encaminhadas sob refrigeração ao setor de leptospirose do Departamento de Microbiologia e Parasitologia no Instituto Biomédico da Universidade Federal Fluminense. Após retração do coágulo, as amostras foram centrifugadas a 2500 rpm para obtenção do soro e estes congelados em freezer vertical a $-20^{\circ} \mathrm{C}$ até a realização dos exames.

Antígenos - Utilizou-se para o diagnóstico sorológico de leptospirose o teste da Soroaglutinação Microscópica com Antígenos Vivos, conforme recomendação da OMS (Faine et al., 2000). Como antígenos, utilizaram-se culturas vivas de leptospiras com quatro a 14 dias de crescimento e densidade de aproximadamente 100 a 200 microrganismos por campo microscópico, mantidas a $280 \mathrm{C}$ em meio líquido $\mathrm{EMJH}$ enriquecido com albumina bovina. Antes da realização dos testes, as culturas eram examinadas em campo escuro a fim de evitar a utilização dos antígenos com contaminação, autoaglutinação ou mortalidade de leptospiras. Os antígenos utilizados foram todos da espécie Leptospira interrogans serovares Autumnalis (Akiyami A), Bratislava (Jez-Bratislava), Bataviae (Van Tienen), Canicola (Hond Utrecht IV), Grippotyphosa (Moska V), Icterohaemorrhagiae (RGA), Copenhageni (M 20) e Pomona (Pomona).

Método - O teste consiste na diluição dos soros em solução salina fisiológica na proporção de 1:50 e posterior adição à cultura de antígenos, de forma a obter-se uma diluição de 1:100, com incubação em estufa a 37oC por três horas e exame em microscópio óptico simples equipado com condensador de campo escuro a seco. As amostras foram consideradas reativas quando apresentavam um mínimo de $50 \%$ de leptospiras aglutinadas; estas foram então diluídas e tituladas a partir de 100 até 800 . Os soros que ainda apresentaram forte reação a este título foram caracterizados como "títulos maiores que 800". Considerou-se a reatividade de um soro para o serovar em que se observou a aglutinação na maior diluição deste soro. Baseando-se nos títulos alcançados, os soros foram classificados em Grupo A, ou fortemente reativos, com titulação mínima de 800, Grupo B, ou reativos, com títulos entre 200 e 400, e Grupo C, ou negativos, com títulos inferiores a 200.

\section{Resultados e discussão}

Uma vez que a leptospirose é endêmica em áreas tropicais como o município do Rio de Janeiro, considerou-se como ponto de corte, no presente estudo, o título de anticorpos antiLeptospira iguais ou superiores a 200. Em países onde a leptospirose não é freqüente, e, portanto a possibilidade de contatos prévios com a bactéria é bastante reduzida, animais com títulos da ordem de 100 já são considerados reativos (Faine et al., 2000).

Desta forma, das 120 amostras examinadas, 88 (73,3\%) foram reativas à prova de soroaglutinação microscópica com antígenos vivos para diagnóstico de leptospirose. Baseandose nos títulos alcançados, os soros foram classificados em Grupo A, ou fortemente reativos, com titulação mínima de 800 (25 animais $-20,8 \%$ ), Grupo B, ou reativos (63 animais $-52,5 \%$ ), com títulos entre 200 e 400, e Grupo C, ou negativos (32 animais - 26,7\%), com títulos inferiores a 200.

No que se refere à distribuição por serovares, verificou-se amplo predomínio de sororreatividade para a amostra Icterohaemorrhagiae, com 60 amostras reativas para este serovar (50\%), seguido de Copenhageni, que apresentou 19 amostras reativas $(15,8 \%)$ e Canicola, com nove amostras reativas $(7,5 \%)$. Ao somar-se as amostras reativas para Icterohaemorrhagiae e Copenhageni, por serem ambas estirpes do mesmo sorogrupo, obtiveram-se 79 amostras sororreativas para este sorogrupo, o que corresponde a $78,4 \%$ das amostras reativas e $57,5 \%$ dos animais estudados. Nenhuma amostra apresentou sororeatividade para os serovares Autumnalis, Bataviae, Grippotyphosa, Pomona ou Bratislava (Tabela 1). 
Tabela 1: Distribuição da freqüência de soros testados a diferentes serovares de Leptospira interrogans de acordo com a intensidade da reação

\begin{tabular}{lccccc}
\hline & $<\mathbf{2 0 0}$ & $\mathbf{2 0 0}$ & $\mathbf{4 0 0}$ & $\mathbf{9 0 0}$ & TOTAL \\
\hline Icterohaemorrhagiae & 25 & 24 & 25 & $\mathbf{9 0}$ \\
Copenhageni & 5 & 4 & 6 & 4 & $\mathbf{1 9}$ \\
Canicola & 2 & 1 & 3 & 2 & $\mathbf{8}$ \\
Bataviae & - & - & - & - & - \\
Bratislava & - & - & - & - & - \\
Autimnalis & - & - & - & - & - \\
Grippotyphosa & - & - & - & - & - \\
Pomona & - & - & - & - & $\mathbf{2 0}$ \\
\hline TOTAL & $\mathbf{3 2}$ & $\mathbf{2 9}$ & $\mathbf{3 4}$ & & \\
\hline Conclusão & Negativos & Reativos & Reativos & Fortemente Reativos & \\
\hline
\end{tabular}

Inquéritos sorológicos realizados no Brasil mostram cães com índices de sororreatividade de 15 a 17\% (Favero et al., 2002; Hagiwara et al., 2004). O resultado obtido no presente trabalho é superior ao encontrado por outros estudos conduzidos com animais clinicamente doentes, como os de Lilenbaum et al. (1994) e Prescott et al. (2002) que citam índices de $64,1 \%$ e $45,3 \%$ respectivamente. Esse achado é suportado por uma adequada anamnese e exame conduzidos pelo clínico, o que justifica os elevados índices encontrados e demonstra a capacidade dos clínicos em reconhecer a enfermidade a partir de seus sinais clínicos.

Em relação à freqüência dos serovares observados na soroaglutinação microscópica com antígenos vivos, houve predomínio dos serovares Icterohaemorrhagiae e Copenhageni, ambos do sorogrupo Icterohaemorrhagiae. Estes dados concordam com os estudos realizados no Brasil por Avila et al. (1980) e Favero et al. (2002) que também incriminaram estes

\section{Referências}

ABUCHAIM, D. M. Comparação entre os resultados obtidos em cães suspeitos e assintomáticos no diagnóstico laboratorial da leptospirose. Arq. Fac. Vet. UFRGS, v. 14, p. 5-9, 1986.

ALVES, B. A., SOUZA, E. T., LILENBAUM, W. Incidência do serovar andamana em leptospirose canina no Rio de Janeiro, Brasil. Cienc. Med, v. 8, n. 1, p. 27-30, 1989.

AVILA, F.A., PINTO, G.C., PECEGO, C.E.V, SILVA JUNIOR, C.O. Freqüência de aglutininas antileptospiras em cães no município de Jaboticabal, Brasil. In: ENCONTRODE PESQUISAS VETERINÁRIAS, 5. Jaboticabal, 1980. Anais... São Paulo, Sociedade Paulista de Medicina Veterinária, p. 68, 1980.

CALDAS, E. M., SAMPAIO, M. B., BADARO, M. V., SANTOS, M. D., TISHCHENKO, L. M. Leptospirose canina: alguns aspectos sorológicos, laboratoriais e clínicos. Arq. Esc. Vet. UFBA, v. 1, p. 53-66, 1976.

FAINE, S., ADLER, B., BOLIN, C., PEROLAT, P. Leptospira and Leptospirosis. MedSci, Melbourne, Austrália, $2^{\text {nd }}$ ed., 2000.

FAVERO, A. C. M., PINHEIRO, S. R., VASCONCELLOS, S. A., MORAIS, Z. M., FERREIRA, F., NETO, J. S. F. Sorovares de leptospiras predominantes em exames sorológicos de bubalinos, ovinos, caprinos, eqüinos, suínos e cães de diversos estados brasileiros. Cienc. Rural, v. 32, n. 4, p. 613-619, 2002.

GREENE, C. E., MILLER, M. A., BROWN, C. A. Leptospirosis. In:GREENE, C. E. Enfermedades Infecciosas en Perros y Gatos. Philadelphia: Interamericana, 2000. 1014 p. Seção Il: Enfermedades Bacterianas. Cap. 44, p. 302-311.

HAGIWARA, M. K., LUSTOSA, M., KOGIKA, M. M. Leptospirose canina. Vet News, v. XI, n. 67, p. 7-8, 2004. serovares como os mais freqüentemente encontrados em inquéritos sorológicos realizados em amostras de caninos sem suspeita clínica. Em razão de um quadro clínico agudo e severo determinado por estes serovares, os cães são encaminhados a atendimento veterinário com maior freqüência. Não se observou reatividade a nenhum outro serovar testado - Autumnalis, Bataviae, Grippotyphosa, Pomona e Bratislava - resultado este que concorda com os recentes achados de Favero e colaboradores (2002), que também não detectaram reações para estes serovares em 983 cães sadios estudados no estado de São Paulo.

A partir de informações fornecidas pelo veterinário sobre a evolução clínica dos animais após o diagnóstico e tratamento específico com antibióticos pode-se concluir que os 63 cães que representaram o Grupo B, com títulos de anticorpos antiLeptospira entre 200 e 400, efetivamente apresentavam infecção pela Leptospira sp., uma vez que estes animais apresentaram, na sua maioria, melhora clínica após o tratamento específico. Portanto, os principais serovares determinantes de leptospirose canina no Rio de Janeiro são os do sorogrupo Icterohaemorrhagiae e, em menor grau, do serovar Canicola. Uma importante observação diz respeito ao fato de que não houve evidência de reatividade aos serovares Pomona ou Grippotyphosa.

HAGIWARA, M. K., SANTA ROSA, C. A. Leptospirose Canina em São Paulo. Arq. Inst. Biol., v. 42, p. 111-118, 1975.

HEATH, S. E., JOHNSON, R. Leptospirosis. JAVMA, v. 205, n. 11, p. 1518-1523, 1994.

KO, A. I., REIS, M. G., DOURADO, C. M. R., JOHNSON, W. D. J., RILEY, L. W. Urban epidemic of severe leptospirosis in Brazil. The Lancet, v. 354, p. 820-825, sep. 1999.

LEVETT, P. N. Leptospirosis. Clin. Microbiol. Rev., v. 14, p. 296-326, 2001.

LILENBAUM, W., RIBEIRO. V., MARTIN, E., BISPO, V. Estudo sorológico para detecção de anticorpos anti-leptospira em Rattus norvegicus de Duque de Caxias, Rio de Janeiro, Brasil. Rev. Lat. Amer. Microbiol., v. 35, p. 357-360, 1993.

LILENBAUM, W., RIBEIRO, V. L., BRUSTEIN, R. Leptospirose em cães clinicamente suspeitos no Rio de Janeiro, Brasil. A Hora Vet., v. 14, n. 81, p. 48-49, set/out. 1994.

LILENBAUM, W., RISTOW, P. FRÁGUAS, S. A., SILVA, E. D. Evaluation of a rapid slide agglutination test for the diagnosis of acute canine leptospirosis. Rev. Lat. Amer. Microbiol., v. 44, n. 3-4, p. 124-128, 2002. PRESCOTT, J. F., McEWEN, B., TAYLOR, J., WOODS, P., ABRAMSOGG, A., WILCOCK, B. Resurgence of leptospirosis in dogs in Ontario: recent findings. Can Vet. J., v. 43, p. 955-961, 2002.

SANTIN, K., SELLA, A. B., NADVORNY, A., WOLFFENBÜTTEL, S., CARDOSO, M. R., I., SCHMIDT, V. Pesquisa de aglutininas antiLeptospira em cães clinicamente sadios e em cães com suspeita clínica de leptospirose. Clín Vet., n. 60, p. 48-52, 2006. 